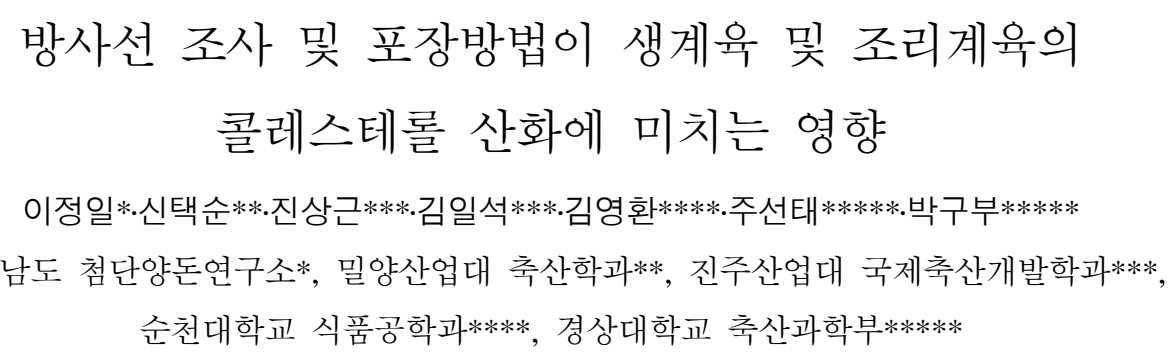

\title{
Effect of Irradiation and Packaging Methods on the Oxidation of Cholesterol in Raw and Cooked Chicken Leg Meat
}

\author{
J. I. Lee*, T. S. Shin**, S. K. Jin***, I. S. Kim***, Y. H. Kim****,
}

\author{
S. T. Joo***** and G. B. Park*****
}

Gyeongnam Province Advanced Swine Research Institute*, Department of Animal Science, Miryang National University**, Department of International Livestock Industry, Jinju National University***, Department of Food Science and Technology, Callage of Agriculture, Sunchon National University****, Division of Animal Science, College of Agriculture, Gyeongsang National University*****

\section{ABSTRACT}

Chicken thigh from a retail market were used as experimental samples. Some chicken samples of raw state were packaged with PVDC at an aerobic and vacuum condition. The other samples were cooked until core temperature arrived at $70^{\circ} \mathrm{C}$ and then packaged immediately in the same way of raw samples. After samples were irradiated by electron beam at $6 \mathrm{kGy}$, they were stored in a refrigerator. Identification and quantity of cholesterol oxides were made at 0 and 7 days of storage, respectively. During the early stage of storage, $7 \beta$ -hydroxycholesterol, a, $\beta$-epoxide, cholestanetriol and 7-ketocholesterol were produced from the raw meat samples, and the production of these chemicals were significantly higher $(1<0.05)$ from the samples with aerobic packaging than those with vacuum packaging. With storage time, 7a-hydroxycholesterol, 6-ketocholesterol and some other chemicals, which were not found during the early stage of storage, were found. Also, the formation of these chemicals were significantly increased $(I<0.05)$ with storage time. Cholesterol and lipid oxidation products of cooked meat after irradiation and irradiated meat after cooking were significantly increased( $(<0.05)$ with storage time for all treatments, and vacuum packaging results in showed significantly lower value $(\mathrm{I}<0.05)$ than aerobic packaging. Summarizing the aforementioned results, it was found that the formation of cholesterol and lipid oxides and lipid oxidation was more easily affected by packaging condition than irradiation.

(Key words : Cholesterol oxides products, Irradiation, Chicken meat)

$\begin{array}{cl}\text { I 서 론 } & \text { 한 요인으로 작용하며, 콜레스테롤이 포함된 } \\ & \text { 식품에서 유리라디칼 반응을 통하여 빛 및 산 }\end{array}$

Corresponding author : Jeong-Ill Lee, Advanced Swine Research Institute, Shinan-Meon, Sanchung-Gun, GyeongNam 666-962, Korea. Tel: 055-970-7481, Fax: 055-970-7479, E-mail : lee1079@empal.com 
콜레스테롤 산화물질은 60가지 이상 발생한다 고 보고하였다(Smith, 1981). 콜레스테롤 산화물 은 생물학적인 조직들에서 많은 부정적인 효과 를 발휘하며, 특히 세포독성, 돌연변이성, 죽종 형성, 발암성을 유발한다고 보고하였으며, 또한 관상동맥질환 및 특정 암을 유발하는 작용을 한다고 보고하였다(Peng 등, 1992ab; Morin과 Peng, 1992; Morin 등, 1992; Addis, 1990; Addis 와 Warner, 1991; Bosinger 등, 1993). 콜레스테 롤 산화물질은 계란 및 건조계란 제품, 우유 및 유제품, 육 및 육제품, 수산식품 및 가공제 품 등에서 발견되었다(Paniangvait 등, 1995). 콜 레스테롤 산화물은 장의 경로를 통해 흡수된다 고 알려져 있으며(Linseisen과 Wolfram, 1998), 콜레스테롤 산화물의 형성에 영향을 미치는 요 인들과 식품에서의 분포는 상당히 흥미로운 일 이다. 콜레스테롤 산화는 유리라디칼에 의하여 진행되며, 그리고 지방산 산화 가속화와 같은 요인들에 의하여 가속화된다(Kowale 등, 1996; Park과 Addis, 1987; Pie 등, 1991)고 보고하였 다. 최근에는 식품안전성에 대한 관심이 증가 됨으로써, 조사의 이용은 안전한 육과 계육을 생산하기 위한 최상의 방법중의 하나로써 잘 받아졌다(Lee 등, 1996). 그러나 육과 계육의 조 사시 문제점은 불쾌취의 발생 그리고 지질산화 를 증가시키며, 이러한 문제점 발생의 강도는 가공조건에 의해 영향을 받는다.

따라서 본 연구에서는 전자선 조사, 가열 및 포장방법이 콜레스테롤 및 지방산화에 미치는 영향을 조사하고 또한, 저장기간이 산화물질에 미치는 영향을 조사하고자 한다.

\section{재료 및 방법}

\section{1. 표준물질과 분석시약}

콜레스테롤과 콜레스테롤 산화물질은 표준 품으로 순도 $99 \%$ 이상의 정제된 시약을 사용 하였다. 즉 cholesterol(cholest-5-en-3ß-ol), 5acholestane(5a-cholestane), 19-hydroxycholesterol (cholest-5-en-3ß-19-diol), 73-hydroxycholesterol (cholest-5-en-3ß, 73-diol), 20a-hydroxycholesterol (5-cholestene-3ß, 20a-diol), a-epoxide(5a, 6aeopxycholestane-3 $\beta$-ol), $\quad \beta$-epoxide $(5 \beta, \quad 6 \beta-$

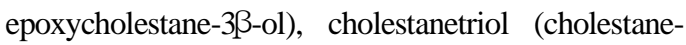
$3 \beta, 5 a, 6 \beta$-triol), 25-hydroxycholesterol(cholestene5-en-3ß-25-diol), 22-ketocholesterol(5-cholesten-3ßol-22-one), 6-ketocholestarol(5a-cholestane-3ßol-6-one), 7-ketocholesterol(5-cholesten-3ß-ol-7-one) 은 Sigma Chemical Co.(St. Louis, MO)로부터 구입하였다. Butylatde hydroxytoluene(BHT) 또한 Sigma Chemical Co.(St. Louis, MO)로부터 구 입하였다. Bis-[trimethylsiyl] trifluoroacetamide (BSTFA) $+1 \%$ trimethylchlorosilane(TMCS)는 Supelco Inc. (Bellefonte, PA)로부터 구입하였고, Celite 545와 calcium phosphate $\left(\mathrm{CaHPO}_{4}-2 \mathrm{H}_{2} \mathrm{O}\right)$ 는 Fisher Scientific Co.(Malvern, PA), 그리고 silicic acid (100-200mesh)는 Aldrich Chemical Co.(Milwaukee, WI)로부터 구입하였다. Hexane, Ethyl acetate, Ethyl ether, Acetone과 Methanol 은 Fisher Scientific Co.(Malvern, PA)로부터 HPLC 등급을 구입하였다. 그리고 다른 모든 용매들은 증류하여 사용하였다.

\section{2. 전자선 처리방법과 저장}

실험재료는 시중에서 판매되는 계육 대퇴부 위를 구입하여 뼈와 껍질을 제거하고 잘게 세 절한 후 생육 시료는 호기적 조건에서 $\mathrm{PVDC}$ 필름 포장과 PVDC 필름 진공 포장하였다. 실 험재료의 전자선 조사는 삼성중공업(주)중앙연 구소 내 전자선 가속기(Model 2LV4)를 이용하 여 실온에서 $1 \mathrm{MeV}$ 의 에너지 수준으로 총 흡수 선량이 $6 \mathrm{kGy}$ 의 총 흡수선량을 얻도록 하였다. 전자선의 투과 깊이가 $4 \mathrm{~mm}$ 이기 때문에 위면과 아래면을 각각 1 회씩 조사하였다. 전자선 조사 처리된 시료는 비조사 대조시료와 함께 2 ${ }^{\circ} \mathrm{C}$ 의 냉장실에 보관하면서 저장기간 별(0, 7일)로 실험에 사용하였다. 전자선 조사 처리 후 가열 처리는 잘게 세절된 시료 $200 \mathrm{~g}$ 을 포장하지 않 고 oven에서 육 내부가 $70^{\circ} \mathrm{C}$ 국내부온도 측정 기 사용)가 될 때까지 가열한 다음 PVDC 필름 을 이용하여 함기포장과 진공포장을 즉시 실시 하였다. 또한 가열 후 전자선 조사를 실시한 
모든 처리구는 생육 시료와 같은 조건으로 2 $4{ }^{\circ} \mathrm{C}$ 냉장실에서 보관하면서 생육 시료와 같 은 저장기간별로 콜레스테롤 산화 생성물의 발 생 종류와 발생량 및 지방산화 정도를 조사하 였다.

\section{3. 지질추출}

계육 시료의 지질 추출은 Folch 등(1957)의 방법에 따라 수행하였다. 육 sample $10 \mathrm{~g}$ 내외를 $50 \mathrm{ml}$ test tube에 넣고 Folch I 용액 $\left(\mathrm{CHCl}_{3}: \mathrm{CH}_{3} \mathrm{OH}\right.$ $=2: 1) 30 \mathrm{ml}$ 와 $\mathrm{BHT}(7.2 \%) 50 \mu \mathrm{l}$ 첨가한 후 polytron(IKA labortechnik T25-B, Malaysia)를 이 용하여 균질화 하였다. 균질화한 후 Folch I 용액 $10 \mathrm{ml}$ 로 polytron을 세척하였으며, 뚜껑을 단단히 막고 냉장온도에서 2시간동안 방치하였 다. $100 \mathrm{ml}$ 메스실린더를 이용하여 균질액을 여 과시키고 여과액의 $25 \%$ 분량을 $0.88 \% \mathrm{NaCl}$ 용 액을 첨가한 다음 마개를 막고 10 회 이상 강하 게 흔들어주었다. 메스실린더의 내부는 Folch II 용액 $\left(\mathrm{CHCl}_{3}: \mathrm{CH}_{3} \mathrm{OH}: \mathrm{H}_{2} \mathrm{O}=3: 47: 48\right)$ $10 \mathrm{ml}$ 로 세척하였다. 층 분리가 완전히 이루어진 다음 상층을 제거하고, 하층인 $\mathrm{CHCl}_{3}$ 은 $50^{\circ} \mathrm{C}$ hot plate 위에서 제거하였다. 제거시키는 동안 6-point mini-vap을 이용하여 $\mathrm{N}_{2}$ 로 flushing하였 다. 추출된 지질은 사용하기 전에 hexane으로 용해한 후 사용하였다.

\section{4. 콜레스테롤 산화 생성물 분리}

Column 준비 : Zubillaga과 maerkeret(1991) 그 리고 Park과 Addis(1985)의 cholesterol oxides 분 리를 위한 column chromatography 방법에 의하 여 실시하였다. 즉, Silicic acid(100mesh), celite 545 , 그리고 $\mathrm{CaHPO}_{4}-2 \mathrm{H}_{2} \mathrm{O}$ 를 $10: 9: 1$ 로 잘 섞 고 chloroform을 첨가하여 혼합물을 만든 다음 glass column $(12 \mathrm{~mm} \times 30 \mathrm{~cm})$ 에 충진하였다. 지 질을 column에 넣고 실험하기 이전에 $10 \mathrm{ml}$ hexane : ethyl acetate $(9: 1 \mathrm{v} / \mathrm{v}$, solvent $\mathrm{I})$ 를 첨 가하였다.

시료 준비 : Folch 등(1957)의 방법으로 추출 된 지질을 column에 $0.2 \mathrm{~g}$ 넣은 후, 중성지질과
콜레스테롤(인지질)을 제거시키기 위하여 $50 \mathrm{ml}$ solvent I과 60ml solvent II(hexane : ethyl acetate = 4:1)를 column에 통과시켰다. Column 속에 있는 콜레스테롤 산화물을 추출하기 위하여 40ml solvent III(acetone : ethyl acetate : methanol = 50:50:5)를 $1 \mathrm{ml} / \mathrm{min}$ 의 유속으로 흐르게 하 여 회수하였다. 최종 회수한 solvent III 질소 충진을 하면서 $50^{\circ} \mathrm{C}$ ot plate에서 건조시켰다. 최 종 건조된 cholesterol oxides에 $200 \mu \ell$ pyridine과 $100 \mu \ell$ sylon BFT(Bis-[trimethylsiyl] trifluoroacetamide (BSTFA) $+1 \%$ trimethylchlorosilane(TMCS))를 첨 가하여 $80^{\circ} \mathrm{C}$ 서 1 시간 동안 가열하여 BSTFA/ TMCS 유도체를 만들었다.

\section{5. 콜레스테롤 산화물 분석}

콜레스테롤 산화물 분석은 capillary column injection과 FID detection이 설치된 Hewlettp Packard(HP; \#142 Avendia Felipe, Anaheim. CA. 92807. U.S.A) 6890으로 수행하였다. Column은 $0.32 \mathrm{~mm} \quad$ I.D. $X \quad 30 \mathrm{~m}$ length $\times 0.33 \mu \mathrm{m}$ film thickness (Supelcowax 10 column)을 사용하였다. Carrier gas는 helium을 사용하였으며, 유속은 $1.6 \mathrm{ml} / \mathrm{min}$ 로 하였다. 그리고 head pressure는 $14.0 \mathrm{psi}$, oven의 initial 온도는 $70^{\circ} \mathrm{C}$ 며, 0.5 분간 유지시킨 후, 분당 $40^{\circ} \mathrm{C}$ 증가시켜 $275^{\circ} \mathrm{C}$-지 증가시킨 후 0.5 분간 유지시킨 후 분당 $2^{\circ} \mathrm{C}$ 증가시켜 $280^{\circ} \mathrm{C}$-지 온도를 상승시켰다. Injection과 detector 온도는 $300^{\circ} \mathrm{C}$. 설정하였고, 시 료의 주입량은 $0.5 \mu$ l 기었다.

\section{6. 지질산화도 측정}

신선육의 산화정도는 Beuge와 Aust(1978) 등 의 방법으로 시료 $5 \mathrm{~g}$ 에 butylated hydroxyanisole (BHA) $50 \mu \ell$ 증류수 $15 \mathrm{ml}$ 를 가해 polytorn homogenizer(MSE, U. S. A)로 14,000rpm에서 30초 간 균질화시킨 후 균질액 $1 \mathrm{ml}$ 를 시험관에 넣고 여기에 2ml thiobarbituric acid(TBA)/trichloroacetic acid(TCA) 혼합용액을 넣어 완전히 혼합한 다 음, $90^{\circ} \mathrm{C}$ 항온수조에서 15 분간 열처리한 후 냉각시켜 $3,000 \mathrm{rpm}$ 에서 10 분간 원심분리 시켰 
다. 원심분리한 sample의 상층을 회수하여 spectrophotometer 531nm에서 흡광도를 측정했다.

$$
T B A R S=\text { 흡광도 수치 } \times 5.88
$$

\section{7. 통계분석}

SAS(1995) 통계 프로그램을 이용하여 분산분 석과 Duncan의 다중검정을 수행하였다.

\section{III 결과 및 고찰}

\section{1. 전자선 처리된 생육}

\section{(1) 포장조건이 콜레스테롤 산화물질 생성에 미치는 영향}

가열하지 않은 계육 대퇴부위를 함기 및 진 공 포장하여 전자선 조사를 실시한 후 저장기 간의 경과에 따른 콜레스테롤 산화물질의 발생
종류와 발생량의 결과는 Table 1에 나타내었다. 저장 0 일째에 함기포장한 후 전자선 조사를 실 시하지 않은 처리구에서는 7ß-hydroxycholesterol, $a \cdot \beta$-epoxide,과 7-ketocholesterol 만이 검출되 었지만 전자선 조사 처리구에서는 이상의 발생 종류 외에 cholestanetriol이 검출되었다. 7ß-hy droxycholesterol 발생량은 처리구간에 유의적인 차이는 없었지만 함기포장하여 전자선 조사한 처리구가 다른 처리구에 비하여 발생량이 많았 다. 함기포장하여 전자선 조사를 실시한 처리구 에서 발생된 $a \cdot \beta$-epoxide와 cholestanetriol은 다른 처리구에 비하여 높은 발생량을 보였다. 7-ketocholesterol의 발생량은 진공포장하여 전자 선 조사를 실시한 처리구는 $11.1 \mu \mathrm{g}$;였지만 함 기포장 처리구와 함기포장하여 전자선 조사를 실시한 처리구는 각각 12.5 와 $17.2 \mu \mathrm{g}$; 발생하였 다. 전체 발생량은 진공포장한 후 전자선 조사를 실시한 처리구가 유의적으로 낮은 발생량을 보였 다. 저장 7 일째는 저장 0 일째와 비교하여 많은

Table 1. Effect of packaging conditions on cholesterol oxides products

\begin{tabular}{|c|c|c|c|c|c|c|c|c|}
\hline \multicolumn{9}{|c|}{ Raw meat } \\
\hline & \multicolumn{4}{|c|}{0 day( $\mu \mathrm{g}$ JOPs/g lipid) } & \multicolumn{4}{|c|}{7 days( $\mu \mathrm{g}$ JOPs/g lipid) } \\
\hline COPs & $\mathrm{A}-\mathrm{C}$ & A-IR & V-IR & SEM & $\mathrm{A}-\mathrm{C}$ & A-IR & V-IR & SEM \\
\hline 7a-hy & $0.0^{\mathrm{Y}}$ & $0.0^{\mathrm{Y}}$ & $0.0^{\mathrm{Y}}$ & - & $33.2^{\mathrm{BX}}$ & $51.3^{\mathrm{AX}}$ & $10.5^{\mathrm{CX}}$ & 3.894 \\
\hline 19-hy & 0.0 & 0.0 & 0.0 & - & 0.0 & 0.0 & 0.0 & - \\
\hline 7ß-hy & $21.2^{\mathrm{Y}}$ & $27.5^{\mathrm{Y}}$ & 22.7 & 2.859 & $42.0^{\mathrm{BX}}$ & $60.4^{\mathrm{AX}}$ & $17.6^{\mathrm{C}}$ & 3.914 \\
\hline 20a-hy & 0.0 & 0.0 & 0.0 & - & 0.0 & 0.0 & 0.0 & - \\
\hline$\beta$-ер & $8.5^{\mathrm{ABY}}$ & $10.0^{\mathrm{AY}}$ & $7.1^{\mathrm{B}}$ & 0.634 & $16.8^{\mathrm{BX}}$ & $33.2^{\mathrm{AX}}$ & $7.0^{\mathrm{CX}}$ & 1.986 \\
\hline a-ep & $4.0^{\mathrm{A}}$ & $4.7^{\mathrm{AY}}$ & $\mathrm{TR}^{\mathrm{B}}$ & 0.311 & $6.5^{\mathrm{B}}$ & $10.1^{\mathrm{AX}}$ & $\mathrm{TR}^{\mathrm{C}}$ & 1.016 \\
\hline triol & $0.0^{\mathrm{BY}}$ & $5.3^{\mathrm{A}}$ & $\mathrm{TR}^{\mathrm{B}}$ & 0.605 & $4.5^{\mathrm{AX}}$ & $5.1^{\mathrm{A}}$ & $\mathrm{TR}^{\mathrm{B}}$ & 0.523 \\
\hline 25-hy & 0.0 & 0.0 & 0.0 & - & 0.0 & 0.0 & 0.0 & - \\
\hline 22-keto & 0.0 & 0.0 & 0.0 & - & 0.0 & 0.0 & 0.0 & - \\
\hline 6-keto & 0.0 & $0.0^{\mathrm{Y}}$ & $0.0^{\mathrm{Y}}$ & - & $0.0^{\mathrm{B}}$ & $\mathrm{TR}^{\mathrm{AX}}$ & $\mathrm{TR}^{\mathrm{AX}}$ & - \\
\hline 7-keto & $12.5^{\mathrm{BY}}$ & $17.2^{\mathrm{AY}}$ & $11.1^{\mathrm{B} 1)}$ & 0.960 & $29.8^{\mathrm{BX}}$ & $54.0^{\mathrm{AX}}$ & $8.7^{\mathrm{B}}$ & 6.973 \\
\hline Total & $46.2^{\mathrm{BY}}$ & $64.7^{\mathrm{AY}}$ & $40.9^{\mathrm{B}}$ & 4.820 & $132.8^{\mathrm{BX}}$ & $214.1^{\mathrm{AX}}$ & $43.8^{C}$ & 15.016 \\
\hline
\end{tabular}

${ }^{1)} \mathrm{TR}$, trace(below $0.5 \mu \mathrm{g}$ ); A, aerobic packaging; V, vacuum packaging; C, nonirradiated; IR, irradiated at $6 \mathrm{kGy}$ dose; SEM., standard error of the mean.

${ }^{A, B, C}$ Means \pm SD not sharing a common superscript in the same row in the same treatment are significantly different $(\mathrm{P}<0.05)$.

${ }^{\mathrm{X}, \mathrm{Y}}$ Means $\pm \mathrm{SD}$ not sharing a common superscript in the same row in the storage days are significantly different $(\mathrm{P}<0.05)$.

Abbreviation : 7a-hy, 7a-hydroxycholesterol; 19-hy, 19-hydroxycholesterol; 73-hy, 73-hydroxycholesterol; 20a -hy, 20a-hydroxycholesterol; $\beta$-ep, $\quad \beta$-epoxide; a-ep, a-epoxide; triol, cholestanetriol; 25-hy, 25hydroxycholesterol; 22-keto, 22-ketocholesterol; 6-keto, 6-ketocholesterol; 7-keto, 7-ketocholesterol. 
종류의 콜레스테롤 산화물질이 발생하였는데, 저 장 0일째에 발생되지 않은 7a-hydroxycholesterol 과 6-ketocholesterol이 검출되었다. Hwang과 Maerker(1993b)은 $10 \mathrm{kGy}$ 의 선량으로 신선 계육 을 조사하였을 때 비조사계육 수준에 비하여 대략 4배 가량 6-ketocholesterol이 검출되었다고 보고하였다. Lai 등(1995)은 계란 분말에서 5가 지 콜레스테롤 산화물질을(a-와 $\beta$-epoxides, 7a-와 7ß-hydroxycholesterol, 그리고 7-ketochol esterol) 분리하였는데, 본 실험에서 발생된 종 류와 거의 일치하였다.

발생된 콜레스테롤 산화물질에서 처리구간의 차이를 비교하였을 때 함기포장하여 조사를 실 시한 처리구가 타 처리구에 바하여 유의적으로 $(\mathrm{P}<0.05)$ 많은 발생량을 보였다. 다음으로는 함 기포장 처리구가 많은 발생량을 보였다. 1990 년 이후 식품의 안정성에 대한 관심이 고조되 면서 위생적인 식품생산을 위한 방법으로 감마 선 및 전자선 조사를 실시하였으며, Grants (1996)는 생육에서 병원성 미생물을 통제하는 가장 효과적인 방법이 조사(irradiation)라고 하 였다. 그러나 조사된 육에서의 주된 관심은 조 사 동안 불쾌취(off-odor)의 발생과 지질산화의 원인이 되는 hydroxyl radicals을 발생시켜 육 품질에 영향을 미친다. 조사된 생육 또는 가열 육에서의 지질산화의 발생 정도는 포장, 저장 그리고 조사 전 - -의 가공조건에 의해 영향을 받는다고 보고하였다(Ahn 등, 1998). 본 연구의 결과 진공포장하여 조사를 실시하면 조사되지 않은 함기포장 육에 비하여 콜레스테롤 산화를 억제시킬 수 있다고 사료된다.

\section{(2) 포장조건이 지방산화에 미치는 영향}

함기 및 진공 포장하여 전자선 조사를 실시 한 후 저장기간의 경과에 따른 지방산화 정도 를 조사한 결과는 Table 2에 나타내었다. 저장 초기에는 전자선 조사를 실시하지 않은 처리구 가 유의적으로( $<0.05)$ 낮은 지방산화를 보였 으며, 다음으로 진공포장하여 조사한 처리구와 함기포장하여 조사한 처리구 순이었다. 모든 처리구가 저장기간이 경과함에 따라 지방산화 가 유의적으로 $(\mathrm{I}<0.05)$ 증가하는 결과를 보였
Table 2. Effect of packaging conditions on lipid oxidation(mg MDA/kg)

\begin{tabular}{clcc}
\hline \multicolumn{4}{c}{ Raw meat } \\
\hline Treatment $^{1)}$ & 0 day & 7 days & SEM \\
\hline \hline A-C & $1.40^{\mathrm{CY}}$ & $5.31^{\mathrm{BX}}$ & 0.299 \\
$\mathrm{~A}-\mathrm{IR}$ & $3.66^{\mathrm{AY}}$ & $10.61^{\mathrm{AX}}$ & 0.076 \\
V-IR & $1.72^{\mathrm{B}}$ & $1.78^{\mathrm{C}}$ & 0.080 \\
\hline SEM & 0.065 & 0.252 \\
\hline
\end{tabular}

1) A, aerobic packaging; V, vacuum packaging; C, nonirradiated; IR, irradiated at 6kGy dose; SEM., standard error of the mean.

${ }_{\mathrm{A}, \mathrm{B}, \mathrm{C}}$ Means $\pm \mathrm{SD}$ not sharing a common superscript in the same row in the same treatment are significantly different $(\mathrm{I}<0.05)$.

${ }^{\mathrm{X}, \mathrm{Y}}$ Means $\pm \mathrm{SD}$ not sharing a common superscript in the same row in the storage days are significantly different $(\mathrm{I}<0.05)$.

다. 저장 7일째에는 저장초기와는 달리 진공포 장한 후 조사 처리구가 가장 낮은 지방산화를 보였다. 2차 산화물(TBARS)은 조리된 돈육 (Monahan 등, 1992)과 전유분말(Chan 등, 1993) 에서도 저장기간 동안 TBARS 생성이 콜레스 테롤 산화 생성물의 발생과 유사한 경향을 보 인다고 보고하였다. 육의 TBARS는 육에 있어 콜레스테롤 전체 함량과 그리고 다중불포화지 방산의 함량과 높은 상관이 있다고 보고하였다 (Angulo 등, 1997; Galvin 등, 1998).

\section{2. 전자선 조사 후 가열된 계육}

(1) 조사시 포장조건과 저장시 포장조건이 콜레스테롤 산화물질 생성에 미치는 영향 전자선 조사 후 조리된 계육 대퇴부위의 포장방법에 따른 콜레스테롤 산화물의 발생 종류와 발생량의 변화는 Table 3 에 나타내었 다. 저장 0 일에는 $7 \mathrm{a}$-hydroxycholesterol, $7 \beta$ hydroxycholesterol, $a \cdot \beta$-epoxide, cholestanetriol 및 7-ketocholesterol이 검출되었다. 처리구간의 비교에서는 진공포장하여 조사 후 가열하여 즉 시 진공포장한 처리구가 가장 낮은 콜레스테롤 산화물질 발생량을 보였으며(62.55 $\mu \mathrm{g}$ ), 유의적 으로 가장 많은 콜레스테롤 산화물질이 생성된 처리구는 함기포장하여 조사를 실시한 후 가열 
Table 3. Effect of packaging conditions on cholesterol oxidation products in irradiated meat during storage

\begin{tabular}{|c|c|c|c|c|c|c|c|}
\hline \multicolumn{8}{|c|}{ Cooking after irradiation } \\
\hline & \multicolumn{7}{|c|}{0 day( $\mu \mathrm{g}$ JOPs/g lipid) } \\
\hline COPs & A-C-V & A-C-A & A-IR-V & A-IR-A & V-IR-V & V-IR-A & SEM \\
\hline 7a-hy & $0.0^{\mathrm{BY}}$ & $25.3^{\mathrm{AY}}$ & $22.7^{\mathrm{A}}$ & $28.2^{\mathrm{AY}}$ & $16.7^{\mathrm{A}}$ & $22.7^{\mathrm{AY}}$ & 3.161 \\
\hline 19-hy & 0.0 & 0.0 & 0.0 & 0.0 & 0.0 & 0.0 & - \\
\hline 7ß-hy & $29.8^{\mathrm{AB}}$ & $41.2^{\mathrm{AY}}$ & $31.2^{\mathrm{ABX}}$ & $35.4^{\mathrm{ABY}}$ & $22.1^{\mathrm{B}}$ & $29.7^{\mathrm{ABY}}$ & 3.386 \\
\hline 20a-hy & 0.0 & 0.0 & 0.0 & 0.0 & 0.0 & 0.0 & - \\
\hline$\beta$-ер & $11.0^{\mathrm{B}}$ & $16.9^{\mathrm{AY}}$ & $12.6^{\mathrm{ABX}}$ & $18.1^{\mathrm{AY}}$ & $9.7^{\mathrm{B}}$ & $13.9^{\mathrm{ABY}}$ & 1.383 \\
\hline a-ep & $4.9^{\mathrm{AX}}$ & $5.1^{\mathrm{AY}}$ & $3.2^{\mathrm{BX}}$ & $5.6^{\mathrm{AY}}$ & $\mathrm{TR}^{\mathrm{C}}$ & $4.4^{\mathrm{ABY}}$ & 0.423 \\
\hline triol & TR & $\mathrm{TR}^{\mathrm{Y}}$ & TR & $\mathrm{TR}^{\mathrm{Y}}$ & TR & $\mathrm{TR}^{\mathrm{Y}}$ & - \\
\hline 25-hy & 0.0 & 0.0 & 0.0 & 0.0 & 0.0 & 0.0 & - \\
\hline 22-keto & 0.0 & 0.0 & 0.0 & 0.0 & 0.0 & 0.0 & - \\
\hline 6-keto & 0.0 & 0.0 & 0.0 & 0.0 & 0.0 & 0.0 & - \\
\hline 7-keto & $17.0^{\mathrm{BC}}$ & $25.6^{\mathrm{ABY}}$ & $21.2^{\mathrm{ABCX}}$ & $27.8^{\mathrm{AY}}$ & $14.0^{\mathrm{C}}$ & $22.0^{\mathrm{ABCY}}$ & 2.108 \\
\hline Total & $62.7^{\mathrm{B}}$ & $113.5^{\mathrm{AY}}$ & $91.0^{\mathrm{ABX}}$ & $115.1^{\mathrm{AY}}$ & $62.5^{\mathrm{B}}$ & $92.7^{\mathrm{ABY}}$ & 9.794 \\
\hline \multicolumn{8}{|c|}{ Cooking after irradiation } \\
\hline & \multicolumn{7}{|c|}{7 days( $\mu$ g JOPs/g lipid) } \\
\hline COPs & $\mathrm{A}-\mathrm{C}-\mathrm{V}$ & A-C-A & A-IR-V & A-IR-A & V-IR-V & V-IR-A & SEM \\
\hline 7a-hy & $19.9^{\mathrm{CX}}$ & $72.0^{\mathrm{BX}}$ & $17.8^{\mathrm{C}}$ & $89.9^{\mathrm{AX}}$ & $16.4^{\mathrm{C}}$ & $67.4^{\mathrm{BX}}$ & 4.226 \\
\hline 19-hy & 0.0 & 0.0 & 0.0 & 0.0 & 0.0 & 0.0 & - \\
\hline 7ß-hy & $26.8^{\mathrm{B}}$ & $86.8^{\mathrm{AX}}$ & $22.4^{\mathrm{BY}}$ & $101.5^{\mathrm{AX}}$ & $19.6^{\mathrm{B}}$ & $83.1^{\mathrm{AX}}$ & 5.151 \\
\hline 20a-hy & 0.0 & 0.0 & 0.0 & 0.0 & 0.0 & 0.0 & - \\
\hline$\beta$-ер & $11.7^{\mathrm{C}}$ & $49.2^{\mathrm{AX}}$ & $9.5^{\mathrm{CY}}$ & $55.6^{\mathrm{AX}}$ & $7.1^{\mathrm{C}}$ & $38.8^{\mathrm{BX}}$ & 3.099 \\
\hline a-ep & $\mathrm{TR}^{\mathrm{BY}}$ & $13.7^{\mathrm{AX}}$ & $\mathrm{TR}^{\mathrm{BY}}$ & $15.1^{\mathrm{AX}}$ & $\mathrm{TR}^{\mathrm{B}}$ & $13.4^{\mathrm{AX}}$ & 0.985 \\
\hline triol & $\mathrm{TR}^{\mathrm{C}}$ & $6.6^{\mathrm{BX}}$ & $\mathrm{TR}^{\mathrm{C}}$ & $11.5^{\mathrm{AX}}$ & $\mathrm{TR}^{\mathrm{C}}$ & $10.5^{\mathrm{BX}}$ & 1.196 \\
\hline 25-hy & 0.0 & 0.0 & 0.0 & 0.0 & 0.0 & 0.0 & - \\
\hline 22-keto & 0.0 & 0.0 & 0.0 & 0.0 & 0.0 & 0.0 & - \\
\hline 6-keto & 0.0 & 0.0 & 0.0 & 0.0 & 0.0 & 0.0 & - \\
\hline 7-keto & $18.1^{\mathrm{B}}$ & $103.0^{\mathrm{AX}}$ & $13.9^{\mathrm{BY}}$ & $122.4^{\mathrm{AX}}$ & $16.4^{\mathrm{B}}$ & $97.6^{\mathrm{AX}}$ & 9.170 \\
\hline Total & $76.5^{C}$ & $331.3^{\mathrm{BX}}$ & $63.6^{\mathrm{CY}}$ & $396.0^{\mathrm{AX}}$ & $59.5^{\mathrm{C}}$ & $310.8^{\mathrm{BX}}$ & 17.901 \\
\hline
\end{tabular}

1) TR, trace(below 0.5 $\mu \mathrm{g}$ !); A, aerobic packaging; V, vacuum packaging; C, nonirradiated; IR, irradiated at 6kGy dose; SEM., standard error of the mean.

$\mathrm{A}, \mathrm{B}, \mathrm{C}$ Means $\pm \mathrm{SD}$ not sharing a common superscript in the same row in the same treatment are significantly different $(\mathrm{I}<0.05)$.

${ }_{\mathrm{X}, \mathrm{Y}}$ Means $\pm \mathrm{SD}$ not sharing a common superscript in the same row in the storage days are significantly different(I $<$ 0.05).

하여 함기포장한 처리구가 전체 발생량이 115.1 $\mu \mathrm{g}$;으로 가장 많았다. 저장기간이 경과함에 따 라 저장초기에 발생한 산화물질들의 발생량은 급격히 증가하였다. Nourooz-Zadeh와 Appelqvist (1987)는 저장동안 동량 또는 5-10:1의 비율로 a-epoxide보다 $\beta$-epoxide가 많이 발생한다고 보
고하였는데, 본 연구에서도 같은 결과를 얻었다. Pie 등(1991)은 oxysterols 중에서 가장 인체에 해 로운 것은 cholestanetriol, 25-hydroxycholesterol이 며, 발생되지 않거나 또는 아주 적은 량이 산 화로 인하여 발생된다고 하였는데, 저장 초기 에는 trace 정도 검출되었으나, 저장 7일에는 
가열처리하여 함기포장한 처리구들에서는 6.6 $11.5 \mu \mathrm{g}$;의 범위로 검출되어 콜레스테롤 산화에 포장방법이 많은 영향을 미치는 것으로 사료된 다. Nam 등(2001)도 조사된 육을 함기포장하여 보관할 경우 상승적인 작용으로 콜레스테롤 산 화물이 증가한다고 보고하였으며, 조사는 함기 포장의 효과와 비교하였을 때 콜레스테롤의 산 화에 작은 영향을 미친다고 하였다.

(2) 조사시 포장조건과 저장시 포장조건이 지방산화에 미치는 영향

전자선 조사시 포장조건과 가열 후 포장조건 이 지방산화에 미치는 영향을 나타낸 결과는 Table 4에 나타내었다. 저장 0 일에 진공포장하 여 전자선 조사한 두 처리구와 전자선 조사를 하지않은 두 처리구가 타 처리구에 비하여 유 의적으로( $<0.05)$ 낮은 지방산화를 보였으며, 저장기간이 경과함에 따라 모든 처리구의 지방 산화가 증가하였으며, 가열 후 함기포장한 처 리구가 저장기간이 경과함에 따라 유의적으로 ( $<0.05)$ 지방산화가 증가하였다. 처리구간에는 진공포장하여 조사를 실시한 후 가열처리하여

Table 4. Effect of packaging conditions on lipid oxidation in irradiated meat during storage(mg MDA $/ \mathrm{kg}$ )

\begin{tabular}{cccc}
\hline \multicolumn{4}{c}{ Cooking after irradiation } \\
\hline Treatment $^{1)}$ & 0 day & 7 days & SEM \\
\hline \hline A-C-V & $2.52^{\mathrm{C}}$ & $2.79^{\mathrm{D}}$ & 0.082 \\
A-C-A & $3.32^{\mathrm{BY}}$ & $12.13^{\mathrm{BX}}$ & 0.118 \\
A-IR-V & $3.47^{\mathrm{BX}}$ & $2.81^{\mathrm{DX}}$ & 0.081 \\
A-IR-A & $3.92^{\mathrm{AY}}$ & $12.93^{\mathrm{AX}}$ & 0.046 \\
V-IR-V & $2.26^{\mathrm{D}}$ & $2.34^{\mathrm{D}}$ & 0.094 \\
V-IR-A & $2.60^{\mathrm{CY}}$ & $10.15^{\mathrm{CX}}$ & 0.253 \\
\hline SEM & 0.073 & 0.170 \\
\hline
\end{tabular}

1) A, aerobic packaging; V, vacuum packaging; C, nonirradiated; IR, irradiated at $6 \mathrm{kGy}$ dose; SEM., standard error of the mean.

$A, B, C, D$ Means $\pm S D$ not sharing a common superscript in the same row in the same treatment are significantly different( $\mathrm{F}<0.05)$.

${ }^{\mathrm{X}, \mathrm{Y}}$ Means $\pm \mathrm{SD}$ not sharing a common superscript in the same row in the storage days are significantly different $(\mathrm{P}<0.05)$.
즉시 진공포장한 처리구가 유의적으로( $\mathrm{I}<0.05)$ 가장 낮은 지방산화를 보였으며, 전체적으로 가열 후 진공포장하여 저장된 처리구가 함기포 장 처리구에 비하여 유의적으로( $\mathrm{I}<0.05)$ 낮은 지방산화를 보여 전사선 조사처리가 지방산화 에 미치는 영향보다 포장조건이 지방산화에 더 많은 영향을 미치는 것으로 사료된다. 조리된 계육과 칠면조육, 우육, 돈육에서 콜레스테롤 산화물질 발생량과 지질산화물 발생량 사이에 는 양의 상관관계가 있다고 보고하였다(Galvin 등, 1998). Nam 등(2001)도 조사나 포장조건이 지방산화에 많은 영향을 미치며, 진공포장 보 다 함기포장이 지방산화 정도가 심하다고 보고 하였다.

\section{3. 가열 후 전자선 조사된 계육}

(1) 전자선 조사시 포장조건이 콜레스테롤 산화물질에 미치는 영향

가열 처리한 후 전자선 조사시 포장방법에 따른 콜레스테롤 산화물의 발생 종류와 발생량 의 변화는 Table 5

. 가열 처리한

\section{후 저장 0 7a-hydroxycholesterol, 7ß} -hydroxycholesterol, $a \cdot \beta$-epoxide, cholestanetriol 및 7-ketocholesterol 등 6가지 콜레스테롤이 검 출되었으며, 처리구간의 비교에서는 가열처리 한 후 함기포장하여 조사를 실시한 처리구가 유의적으로 $(\mathrm{I}<0.05)$ 가장 높은 발생량을 보였 다. 조사는 미생물 성장을 통제하기 위하여 식 품가공에서 사용되어 왔다. 그러나 수상 또는 오일 유화시스템에서 hydroxy radical을 발생시 키는 것으로 알려져 있다(O'Connell과 Garner, 1983). Lebovics 등(1992)은 이온화 조사는 콜레 스테롤 자동산화와 비슷한 화학적 반응을 야기 시키며, 그리고 조사에 의해 형성된 산화물의 발생량은 조사량에 의존한다고 하였다. $\mathrm{Du}$ 와 $\mathrm{Ahn}(2000)$ 은 조사가 난황분말에서 콜레스테롤 산화물의 형성을 증가시켰으며, 그리고 산소 존재가 콜레스테롤 산화물 형성율에 유의적인 효과를 미친다고 보고하였다.

저장기간이 경과함에 따라 저장초기에 발생 한 산화물질들의 발생량은 급격히 증가하였는 
Table 5. Effect of irradiation and packaging conditions on cholesterol oxidation products

\begin{tabular}{|c|c|c|c|c|c|c|c|c|c|c|}
\hline \multicolumn{11}{|c|}{ Irradiation after cooking } \\
\hline & \multicolumn{5}{|c|}{0 day( $\mu \mathrm{g}$ IOPs/g lipid) } & \multicolumn{5}{|c|}{7 days( $\mu \mathrm{g}$ JOPs/g lipid) } \\
\hline COPs & A-IR & V-IR & $\mathrm{A}-\mathrm{C}$ & $\mathrm{V}-\mathrm{C}$ & SEM & A-IR & V-IR & $\mathrm{A}-\mathrm{C}$ & $\mathrm{V}-\mathrm{C}$ & SEM \\
\hline $7 a-h y$ & $59.2^{\mathrm{A}}$ & $18.9^{\mathrm{BX}}$ & $26.1^{\mathrm{BY}}$ & $23.1^{\mathrm{B}}$ & 2.690 & $57.5^{\mathrm{B}}$ & $14.1^{\mathrm{CY}}$ & $90.4^{\mathrm{AX}}$ & $25.1^{\mathrm{C}}$ & 4.463 \\
\hline 19-hy & 0.0 & 0.0 & 0.0 & 0.0 & - & 0.0 & 0.0 & 0.0 & 0.0 & - \\
\hline 7ß-hy & $74.0^{\mathrm{A}}$ & $26.2^{\mathrm{BX}}$ & $33.8^{\mathrm{BY}}$ & $29.1^{\mathrm{B}}$ & 4.065 & $71.6^{\mathrm{B}}$ & $18.9^{\mathrm{CY}}$ & $98.8^{\mathrm{AX}}$ & $28.5^{\mathrm{C}}$ & 6.505 \\
\hline 20a-hy & 0.0 & 0.0 & 0.0 & 0.0 & - & 0.0 & 0.0 & 0.0 & 0.0 & - \\
\hline$\beta$-ер & $42.1^{\mathrm{A}}$ & $11.0^{\mathrm{B}}$ & $16.1^{\mathrm{BY}}$ & $11.7^{\mathrm{B}}$ & 1.952 & $39.8^{\mathrm{B}}$ & $8.5^{\mathrm{C}}$ & $59.9^{\mathrm{AX}}$ & $10.3^{\mathrm{C}}$ & 4.044 \\
\hline a-ep & $11.4^{\mathrm{A} 1)}$ & $\mathrm{TR}^{\mathrm{D}}$ & $6.4^{\mathrm{BY}}$ & $2.5^{\mathrm{CY}}$ & 0.732 & $10.5^{\mathrm{B}}$ & $\mathrm{TR}^{\mathrm{D}}$ & $17.0^{\mathrm{AX}}$ & $3.9^{\mathrm{CX}}$ & 1.054 \\
\hline triol & $4.6^{\mathrm{A}}$ & $\mathrm{TR}^{\mathrm{B}}$ & $\mathrm{TR}^{\mathrm{BY}}$ & $\mathrm{TR}^{\mathrm{B}}$ & 0.407 & $6.2^{\mathrm{B}}$ & $\mathrm{TR}^{\mathrm{C}}$ & $10.3^{\mathrm{AX}}$ & $\mathrm{TR}^{\mathrm{C}}$ & 0.589 \\
\hline 25-hy & 0.0 & 0.0 & 0.0 & 0.0 & - & 0.0 & 0.0 & 0.0 & 0.0 & - \\
\hline 22-keto & 0.0 & 0.0 & 0.0 & 0.0 & - & 0.0 & 0.0 & 0.0 & 0.0 & - \\
\hline 6-keto & 0.0 & 0.0 & 0.0 & 0.0 & - & 0.0 & 0.0 & 0.0 & 0.0 & - \\
\hline 7-keto & $79.5^{\mathrm{A}}$ & $16.2^{\mathrm{B}}$ & $28.9^{\mathrm{BY}}$ & $18.6^{\mathrm{B}}$ & 3.705 & $91.0^{\mathrm{A}}$ & $11.8^{\mathrm{B}}$ & $123.6^{\mathrm{AX}}$ & $19.0^{\mathrm{B}}$ & 10.031 \\
\hline Total & $270.8^{\mathrm{A}}$ & $72.3^{\mathrm{B}}$ & $111.3^{\mathrm{BY}}$ & $85.0^{\mathrm{B}}$ & 12.150 & $276.6^{\mathrm{B}}$ & $53.3^{C}$ & $400.0^{\mathrm{AX}}$ & $86.7^{\mathrm{C}}$ & 26.350 \\
\hline
\end{tabular}

${ }^{1)} \mathrm{TR}$, trace(below $0.5 \mu \mathrm{g}$;); A, aerobic packaging; V, vacuum packaging; C, nonirradiated; IR, irradiated at $6 \mathrm{kGy}$ dose; SEM., standard error of the mean.

${ }_{\mathrm{A}, \mathrm{B}, \mathrm{C}}$ Means $\pm \mathrm{SD}$ not sharing a common superscript in the same row in the same treatment are significantly different $(\mathrm{I}<0.05)$.

${ }_{\mathrm{X}, \mathrm{Y}}$ Means $\pm \mathrm{SD}$ not sharing a common superscript in the same row in the storage days are significantly different(I 0.05).

데, oxysterols의 함량은 냉장과 동결저장 동안 증가한다고 보고하였다(Kesava Rao 등, 1996; Kowale 등, 1996). 중국식 소시지, 고온에서 건 조된 제품, 자연적으로 발효된 돈육 제품 등의 콜레스테롤 산화는 저장 동안 증가하였지만, 그러나 25-hydroxycholesterol과 cholestanetriol은 검출되지 않았다(Wang 등, 1995)고 보고하였다. 저장 7일 후 처리구간 비교에서는 가열 처리한 후 진공포장한 처리구가 함기포장한 처리구에 비하여 유의적으로( $<$ <0.05) 낮은 콜레스테롤 산화물질이 발생하였다. 식품에서 지질 산화는 철과 구리 같은 금속이온, 산소, 조사, 열처리 그리고 저장 등에 의하여 촉매작용을 할 수 있 으며, 그리고 산소 배제와 항산화제 등으로 산 화를 막을 수 있다. 식품의 가공과 저장 동안 지질산화에 의해 형성된 지질 라디칼은 콜레스 테롤과 생성된 콜레스테롤 산화물의 산화로 가 속화 될 수 있다(Paniangvait 등, 1995). 그러므 로 콜레스테롤의 산화에 항산화제, 가공, 포장 그리고 저장 방법 등의 효과는 생산품 품질을 개선하기 위해서 반드시 확립되어야 한다.
(2) 전자선 조사시 포장조건이 지방산화에 미치는 영향

가열 처리한 후 전자선 조사시 포장방법 이 지방산화에 미치는 영향을 나타낸 결과 는 Table 6에 나타내었다. 저장 0 일째 처리 구간의 비교에서 함기포장하여 조사한 처리 구가 유의적으로 $(\mathrm{I}<0.05)$ 가장 높은 지방산 화를 보였는데, 이 결과는 Table 5 의 결과에 서 보여준 콜레스테롤 산화와 유사한 결과 였다. 저장기간이 경과함에 따라 모든 처리 구의 지방산화가 증가하였다. 저장 7 일째 처 리구간의 비교에서 함기포장한 처리구가 진 공포장한 처리구에 비하여 유의적으로( < $0.05)$ 지방산화가 증가하였다. Nam 등(2001) 은 콜레스테롤 산화물과 지방산화는 강하게 양의 상관관계를 가진다고 보고하였다. 콜 레스테롤 산화물질과 지방산화물(TBARS)의 발생량은 거의 유사한 경향을 보이며, 육에 있어 산화물질의 발생량은 포화지방산의 비 율과 밀접한 관련이 있다고 하였다(Ahn 등, 2001). 
Table 6. Effect of irradiation and packaging conditions on lipid oxidation(mg MDA/kg)

\begin{tabular}{cccc}
\hline \multicolumn{4}{c}{ Irradiation after cooking } \\
\hline Treatment $^{1)}$ & 0 day & 7 days & SEM \\
\hline \hline A-IR & $7.94^{\mathrm{AY}}$ & $11.72^{\mathrm{BX}}$ & 0.267 \\
V-IR & $2.17^{\mathrm{B}}$ & $2.38^{\mathrm{C}}$ & 0.128 \\
$\mathrm{~A}-\mathrm{C}$ & $2.73^{\mathrm{BY}}$ & $13.30^{\mathrm{AX}}$ & 0.379 \\
V-C & $2.65^{\mathrm{B}}$ & $2.76^{\mathrm{C}}$ & 0.068 \\
\hline SEM & 0.159 & 0.305 & \\
\hline
\end{tabular}

1) A, aerobic packaging; V, vacuum packaging; C, nonirradiated; IR, irradiated at 6kGy dose; SEM., standard error of the mean.

${ }^{\mathrm{A}, \mathrm{B}, \mathrm{C}}$ Means $\pm \mathrm{SD}$ not sharing a common superscript in the same row in the same treatment are significantly different $(I<0.05)$.

${ }^{X, Y}$ Means $\pm S D$ not sharing a common superscript in the same row in the storage days are significantly different $(\mathrm{I}<0.05)$.

\section{IV 요 약}

계육 대퇴부위의 생육 시료는 PVDC 필름으 로 호기적 포장과 진공포장을 하여 $6 \mathrm{kGy}$ 선 량으로 전자선 조사를 실시한 후 2 ${ }^{\circ} \mathrm{C}$ 냉 장실에서 보관하면서 저장기간별 $(0,7$ 일) 실험 에 사용하였다. 전자선 조사 후 가열시료와 가 열 후 전자선 시료는 oven에서 육 내부 온도가 $70^{\circ} \mathrm{C}$ 될 때까지 가열한 다음 함기포장과 진공 포장을 즉시 실시한 후 생육 시료와 같은 조건 으로 냉장실에서 보관하면서 생육 시료와 같은 저장기간별 콜레스테롤 산화물의 발생 종류와 발생량을 조사한 결과는 다음과 같다. 생육 시 료에서 저장초기에는 7ß-hydroxycholesterol a, $\beta$-epoxide, cholestanetriol과 7-ketocholesterol이 검출되었으며, 처리구간에는 함기포장 처리구 가 진공포장 처리구에 비하여 유의적으로( $\mathrm{I}$ $0.05)$ 많은 발생량을 보였다. 저장기간이 경과 함에 따라 저장초기에는 발생되지 않았던 $7 a$ -hydroxycholesterol과 6-ketocholesterol이 검출되 었으며, 발생량도 저장기간이 경과함에 따라 유의적으로 $(\mathrm{I}<0.05)$ 증가하였다. 전자선 조사 후 가열 시료와 가열 후 전자선 조사 시료는
전처리구가 저장기간이 경과함에 따라 콜레스 테롤 산화물과 지질산화물의 발생량이 유의적 으로(I<0.05) 증가하였으며, 처리구간에는 진 공포장한 처리구가 함기포장한 처리구에 비하 여 유의적으로( $<0.05)$ 낮은 발생량을 보였다. 이상의 결과를 종합하면 콜레스테롤 산화물질 과 지질산화물의 발생량은 조사로 인하여 발생 되는 량보다는 저장시 포장조건이 더 많은 영 향을 미치는 것으로 밝혀졌다.

\section{$\mathrm{V}$ 인 용 문 헌}

1. Addis, P. B. 1990. Coronary heart disease: an update with emphasis on dietary lipid oxidation products. Nutr. rev. 62:7.

2. Addis, P. S. and Warner, G. J. 1991. The potential health aspects of lipid oxidation products in food. Ch. 5. In Free Radical and Food Additives, O.I. Aruoma and B. Halliwell (Ed.), p. 77-119. Taylor and Francis L.T.D. London, Great Britain.

3. Ahn, D. U., Nam, K. C., Du, M. and Jo, C. 2001. Effect of irradiation and packaging conditions after cooking on the formation of cholesterol and lipid oxidation products in meats during storage. Meat Sci. 57:413-318.

4. Ahn, D. U., Olson, D. G., Lee, J. I., Jo, C., Wu, C. and Chen, X. 1998. Packaging and irradiation effects on lipid oxidation and volatiles in pork patties. J. Food Sci. 63:15-19.

5. Angulo, A. J., Romera, J. M., Ramirez, M. and Gil, A. 1997. Determination of cholesterol oxides in dairy products. Effect of storage conditions. Journal of Agriculture and Food Chemistry. 45:4318-4323.

6. Beuge, J. A. and Aust, S. D. 1978. Microsomal lipid peroxidation. Methods Enzymol. 52:302-303.

7. Bosinger, S., Luf, W. and Brandl, L. 1993. Oxysterol: their occurrence and biological effects. Int. Dairy J. 3:1-33.

8. Chan, S. H., Gray, J. I. and Gomaa, E. A. 1993. Cholesterol oxidation in whole powders as influenced by processing and packaging. Food Chem. 47:321328.

9. Du, M. and Ahn, D. U. 2000. Effects of antioxidation and color changes of irradiated egg yolk powder. Journal of Food Sci. 65:625-629.

10. Folch, J., Lees, M. and Sloan-Stanley, G. H. 1957. A simple method for the isolation and purification 
of total lipids from animal tissues. J. Bio. Chem. 226:497-507.

11. Galvin, K., Morrissey, P. A. and Buckley, D. J. 1998. Effect of dietary alpha-tocopherol supplement and gamma-irradiation on alpha-tocopherol retention and lipid oxidation in cooked minced chicken. Food Chemistry. 62:185-190.

12. Grants, R. 1996. Pathogen countdown. Meat Poult. Dec. p. S19-45.

13. Hwang, K. T. and Maerker, G. 1993b. Determination of 6-ketocholestanol in unirradiated and irradiated chicken meats. Journal of American Oil Chemists' Society. 70(4):789-792.

14. Kesava Rao, V., Kowale, B. N., Babu, N. P. and Bisht, G. S. 1996. Effect of cooking and storage on lipid oxidation and development of cholesterol oxidation products in water buffalo meat. Meat Sci. 43:179-185.

15. Kowale, B. N., Kesava Reo, V., Babu, N. P., Sharma, N. and Bisht, G. S. 1996. Lipid oxidation and cholesterol oxidation in mutton during cooking and storage. Meat Sci. 43:195-202.

16. Lai, S. M., Gray, J. I. and Zabik, M. E. 1995. Evaluation of solid phase extraction and gas chromatography for determination of cholesterol oxidation products in spray-dried whole egg. J. Agric. Food Chem. 43:1122-1126.

17. Lebovics, V. K., Gaal, O., Somogyi, L. and Farkas, J. 1992. Cholesterol oxides in $\mathrm{\gamma}$-irradiated spraydried egg power. J. Sci. Food Agric. 60:251-254.

18. Lee, M., Sebranek, J. G., Olson, D. G. and Dickson, J. S. 1996. Irradiation and packaging of fresh meat and poultry. J. Food Prot. 59:62-72.

19. Linseisen, J. and Wolfram, G. 1998. Absorption of cholesterol oxidation products from ordinary foodstuffs. Animal of Nutrition and Metabolism. 42:221230.

20. Monahan, F. J., Gray, J. I., Booren, A. M., Miller, E. R., buckley, D. J., Morrissey, P. A. and Gpmaa, E. A. 1992. Influence of dietary treatment on lipid and cholesterol oxidation in pork. J. Agric. Food Chem. 40:1310-1315.

21. Morin, R. J. and Peng, S. K. 1992. Cholesterol oxides in plasma and tissues. Ch. 5, in Biological Effects of Cholesterol Oxides, S. K. Peng and R. J. Morin(Ed.). CRC Press, Ann Arbor, MI.

22. Morin, R. J., Hu, B., Peng, S. K. and Sevanian, A. 1992. Cholesterol oxidation and cancer. Ch. 10, in Biological Effects of Cholesterol Oxides, S.K. Peng and R.J. Morin(Ed.). CRC Press, Ann Arbor, MI.

23. Nam, K. C., Du, M., Jo, C. and Ahn, D. U. 2001. Cholesterol oxidation products in irradiated raw meat with different packaging and storage time. Meat Sci. 58:431-435.

24. Nourooz-Zadeh, J. and Appelqvist, L. A. 1987. Cholesterol in Swedish food ingredients: fresh eggs and dehydrated egg products. J. Food Sci. 52:57-67.

25. O'Connell, M. J. and Garner, A. 1983. Radiation induced generation and the properties of lipid hydroxide in liposomes. Int. J. Radiat. Biol. 44: 615625.

26. Paniangvait, P., King, A. J., Jones, A. D. and German, B. G. 1995. Cholesterol oxides in foods of animal origin. J. Food Sci. 60:11591174.

27. Park, S. W. and Addis, P. B. 1985. HPLC determination of C-7 oxidized cholesterol oxidation derivatives in foods. J. Food Sci. 50:1437-1441.

28. Park, S. W. and Addis, P. B. 1987. Cholesterol oxidation products in some muscle foods. Journal of Food Sci. 52:1500-1503.

29. Peng, S. K., Hu, B. and Morin, R. J. 1992a. Effects of cholesterol oxides on atherogenesis. In: Biological Effects of Cholesterol Oxides, ed Peng, S.K. and Moarin, R. J. CRC Press, Boca Raton, FL, USA. p.167.

30. Peng, S. K., Sevanian, A. and Morin, R. J. 1992b. Cytotoxity of cholesterol oxides. In: Biological Effects of Cholesterol Oxides, ed Peng, S.K. and Moarin, R.J. CRC Press, Boca Raton, FL, USA. p.147.

31. Pie, J. E., Spahis, K. and Seillan, C. 1991. Cholesterol oxidation in meat products during cooking and frozen storage. J. Agric. Food Chem. 39:250-254.

32. SAS. 1995. SAS/SATT Software for PC. Release 6.11, SAS Institute, Cray, NC, U.S.A.

33. Smith, L. L. 1981. Cholesterol autoxidation. Plenum press. New York.

34. Wang, F. S., Jiang, Y. N. and Lin, C. W. 1995. Lipid and cholesterol oxidation in cheese-style sausage using vacuum and modified atmosphere packaging. Meat Sci. 40:93-101.

35. Zubillaga, M. P. and Maerker, G. 1991. Quantification of three cholesterol oxidation products in raw meat and chicken. J. Food Sci. 56:1194-1196.

(접수일자 : 2003. 4. 1. / 채택일자 : 2003. 6. 10.) 